\title{
Prospective study of dietary patterns and chronic obstructive pulmonary disease among US men
}

\author{
Raphaëlle Varraso, Teresa T Fung, Frank B Hu, Walter Willett, Carlos A Camargo
}

Thorax 2007;62:786-791. doi: 10.1136/thx.2006.074534

See end of article for authors' affiliations

Correspondence to: Dr Raphaëlle Varraso, Department of Nutrition, Harvard School of Public Health, 655 Huntington Avenue, Boston Massachusetts O2115, USA; rvarraso@hsph.harvard.edu

Received 3 November 2006 Accepted 15 March 2007

\begin{abstract}
Background: Many foods are associated with chronic obstructive pulmonary disease (COPD) symptoms or lung function. Because foods are consumed together and nutrients may interact, dietary patterns are an alternative way of characterising diet. A study was undertaken to assess the relation between dietary patterns and newly diagnosed COPD in men.

Methods: Data were collected from a large prospective cohort of US men (Health Professionals Follow-up Study). Using principal component analysis, two dietary patterns were identified: a prudent pattern (high intake of fruits, vegetables, fish and whole grain products) and a Western pattern (high intake of refined grains, cured and red meats, desserts and French fries). Dietary patterns were categorised into quintiles and Cox proportional hazards models were adjusted for age, smoking, pack-years, (pack-years) ${ }^{2}$, race/ethnicity, physician visits, US region, body mass index, physical activity, multivitamin use and energy intake.

Results: Between 1986 and 1998, 111 self-reported cases of newly diagnosed COPD were identified among 42917 men. The prudent pattern was inversely associated with the risk of newly diagnosed COPD (RR for highest vs lowest quintile 0.50 (95\% $\mathrm{Cl} 0.25$ to 0.98$)$, $\mathrm{p}$ for trend=0.02), and the Western pattern was positively associated with the risk of newly diagnosed COPD (RR for highest vs lowest quintile $4.56195 \% \mathrm{Cl}$ 1.95 to 10.69), $\mathrm{p}$ for trend $<0.001$ ).

Conclusions: In men, a diet rich in fruits, vegetables and fish may reduce the risk of COPD whereas a diet rich in refined grains, cured and red meats, desserts and French fries may increase the risk of COPD.
\end{abstract}

$C$ hronic obstructive pulmonary disease (COPD) is currently the fourth leading cause of death in Europe and the United States. ${ }^{1}$ With the increase in cigarette smoking in developing countries, it is expected to become the third leading cause of death worldwide by $2020 .^{2}$ Cigarette smoking is the most important risk factor for COPD in developed nations, ${ }^{3}$ but not all smokers develop COPD. ${ }^{4}$ This simple observation suggests that genetic and environmental factors are also involved.

Among environmental factors, changes in diet have been evoked to explain the large increase in COPD. ${ }^{5}$ Several epidemiological studies have suggested that the intake of fruit and other dietary antioxidants is associated with a higher level of lung function ${ }^{6-8}$ or with a lower decline in forced expiratory volume in $1 \mathrm{~s}\left(\mathrm{FEV}_{1}\right)$ or COPD symptoms. ${ }^{9-12}$ Some crosssectional studies have also suggested that a high intake of fish and omega-3 fatty acids is associated with higher lung function and lower COPD symptoms, ${ }^{13}{ }^{14}$ but the only prospective study undertaken did not support this result. ${ }^{9}$

However, all of these studies focused on individual nutrients or foods. Because foods are consumed together and nutrients may interact together, it has been proposed that overall diet should be assessed instead of the individual components. ${ }^{15}$ This approach has been used to investigate the role of diet in several chronic diseases. ${ }^{16}{ }^{17}$ Although one recent study examined the relation between dietary patterns and respiratory phenotypes, ${ }^{18}$ the relation between dietary patterns and newly diagnosed COPD among men remains unknown. Two major dietary patterns were derived in the Health Professionals Follow-up Study (HPFS) and related to coronary heart disease. ${ }^{19}$ The objective of the present analysis is to assess the relation between these dietary patterns and the risk of newly diagnosed COPD in a prospective cohort of $>40000$ US men.

\section{METHODS}

Study population

The HPFS, a prospective cohort study, began in 1986 when 51 529 US health professionals aged 40-75 years answered a detailed mailed questionnaire that included a diet survey and items on lifestyle practice and medical history. Follow-up questionnaires were sent every 2 years thereafter to update information on smoking habits, physical activity, weight and other risk factors, and to ask about newly diagnosed medical conditions. Dietary intake data were collected in 1986 and every 4 years thereafter with a 131-item food frequency questionnaire (FFQ). The study was conducted according to the ethical guidelines of Brigham and Women's Hospital, Boston, USA.

Men who did not satisfy a reported daily energy intake of 3.3-17.6 MJ (800-4200 kcal) or who left blank $>70$ of the 131 food items on the diet questionnaire were excluded, as well as those reporting a history of ever asthma or COPD at baseline. The final baseline population consisted of 42917 men.

\section{Assessment of dietary patterns}

To prepare for factor analysis, food items from the FFQ were grouped into 40 predefined food groups in 1986 and into 42 food groups in 1990 and 1994 (see Appendix A) as previously described. ${ }^{19}$ Dietary patterns were identified from FFQs administered in 1986, 1990 and 1994 using principal component analysis. ${ }^{20}$ Analyses were conducted using the FACTOR procedure in SAS. The factors were rotated by an orthogonal transformation to achieve a simpler structure with greater interpretability, and the number of factors to retain was

Abbreviations: $\mathrm{BMI}$, body mass index; COPD, chronic obstructive pulmonary disease; $F E V_{1}$, forced expiratory volume in $1 \mathrm{~s}$; FFQ, food frequency questionnaire; HPFS, Health Professionals Follow-up Study 
determined using the diagram of eigenvalues. The factor score for each pattern was calculated by summing intakes of food groups weighted by their factor loadings. Factor scores were standardised to have a mean value of 0 and a standard deviation of 1. Factor loadings represent correlation coefficients between the food groups and the particular pattern, with positive loadings representing positive correlations and negative loadings representing inverse correlations. Each man received a factor score for each identified pattern. The resulting factor scores for the Western and prudent dietary patterns were therefore standardised and not correlated with each other. Men with a high intake of the prudent diet might also have a high intake of the Western diet; thus, men with a Western diet and men with a prudent diet are not necessarily two distinct clusters of individuals.

To reduce measurement errors and to represent long-term intake, dietary patterns using all available FFQs were generated and average pattern scores were calculated. The present analysis is based on quintiles of the cumulative average of pattern scores. The cumulative average incorporated repeated measures of diet. With this approach, the 1986 dietary pattern consumption was used to predict newly diagnosed COPD in 1986-90, an average of the 1986 and 1990 dietary pattern consumption was used to predict COPD in 1990-4, and the average of the 1986, 1990 and 1994 dietary pattern consumption was used to predict COPD in 1994-8.

\section{Assessment of respiratory phenotypes}

Because the HPFS includes a large numbers of subjects dispersed throughout the US and is conducted by mail, the diagnosis of COPD was assessed by questionnaire and did not include spirometric testing. Self-reported COPD was defined by the affirmative response to physician-diagnosed chronic bronchitis or emphysema and by the report of a diagnostic test at diagnosis (pulmonary function testing, chest radiography or chest CT scanning). Between 1986 and 1998, 111 cases of newly diagnosed COPD were reported. This epidemiological definition was validated in a random sample of another cohort of health professionals, the Nurses' Health Study. ${ }^{21}$ Using exactly the same questions, the participants' medical records were obtained and reviewed by a physician in a blinded fashion. The diagnosis of COPD was confirmed in $80 \%$ of 218 cases who met this case definition and in $88 \%$ of cases who met this definition and denied a physician diagnosis of asthma. The results of pulmonary function testing were available in the medical records of $71 \%$ of confirmed cases; the mean $\mathrm{FEV}_{1}$ in this group was $50 \%$ predicted.

Asthma was also self-reported and was defined by a doctor diagnosis of asthma and the use of medication for asthma within the past 12 months. Between 1986 and 1998, 212 new cases of adult-onset asthma were reported.

\section{Assessment of other variables}

Information on smoking status was collected every 2 years and categorised into never smokers, ex-smokers and current smokers. We further characterised smokers using their lifetime pack-years of smoking and (pack-years) ${ }^{2}$; previous analyses have shown that the inclusion of both measures optimally controls for the association between smoking and COPD risk. Race/ethnicity was categorised into two classes (white, nonwhite), physician examination was categorised into three classes (no visit, screening, symptoms) and US region was categorised into three classes (East South Central, Mountain and other regions). Body mass index (BMI), physical activity and multivitamin use were assessed every 2 years by selfreported questionnaires. BMI was calculated as weight $/$ height $^{2}$ $\left(\mathrm{kg} / \mathrm{m}^{2}\right)$ and was categorised into seven classes: $\leqslant 20.0$,
$20.0-22.4, \quad 22.5-24.9, \quad 25.0-27.4, \quad 27.5-29.9, \quad 30.0-34.9$, $\geqslant 35.0 \mathrm{~kg} / \mathrm{m}^{2}$. Men also reported the duration of several leisure time physical activities including walking, cycling, swimming or tennis. Physical activity was calculated in metabolic equivalents (METs) per week, where one metabolic equivalent was equal to the energy expended at the basal metabolic rate or at rest. ${ }^{22}$ Total energy intake was calculated from the FFQ and expressed as kcal/day. A job title for each man was recorded: dentist, pharmacist, optometrist, osteopathic physician, podiatrist and veterinarian. Assessment of cardiovascular diseases included angina, myocardial infarction, coronary artery surgery, transient ischaemic attack stroke, or peripheral arterial disease.

\section{Statistical analysis}

Statistical analyses included $\chi^{2}$ tests, analysis of variance, linear regression and Cox proportional hazard regression models. Cox proportional hazards models were adjusted for age, smoking status, pack-years, (pack-years) ${ }^{2}$, race/ethnicity, physician visits, US region, BMI, physical activity, multivitamin use and energy intake. All analyses were conducted using SAS software V9 (Cary, North Carolina, USA).

\section{RESULTS}

\section{Assessment of dietary patterns}

Using principal component analysis, two distinct major dietary patterns were identified at baseline. The first pattern was heavily loaded by a high intake of fruits, vegetables, fish, poultry and whole grain products. The second pattern was heavily loaded by a high consumption of refined grains, cured and red meats, desserts and sweets, French fries, eggs and high-fat dairy products. According to previous studies of dietary patterns in this population, the first pattern was labelled the "prudent" pattern and the second pattern was labelled the "Western" pattern. Similar dietary patterns were identified using FFQs from 1990 and 1994.

The characteristics of the population according to the quintile of both prudent and Western patterns are shown in table 1. Compared with men with the lowest intake of the prudent diet (the lowest quintile), men with the highest intake of the prudent diet (the highest quintile) were more physically active, less likely to be current smokers and took more multivitamin supplements. Men with the highest intake of the prudent diet consumed more polyunsaturated fat, more proteins and more carbohydrates, but less saturated fat and trans fatty acids. As expected, the consumption of fruits, vegetables, whole grains and fish was higher among men with the highest intake of the prudent diet.

At baseline, $46 \%$ of the population were never smokers, $41 \%$ were ex-smokers and only $9 \%$ were current smokers. Among ex-smokers $(n=17585), 70 \%$ had quit smoking at least 10 years before; only $9.5 \%$ had quit in the last 2 years.

Men with the highest intake of the Western diet had a higher BMI, were less physically active, were more likely to smoke and took fewer multivitamin supplements than men with the lowest intake of the Western diet. Men with the highest intake of the Western diet consumed more saturated fat and trans fatty acids but fewer carbohydrates and proteins. As expected, the consumption of cured meat, red meat and desserts and sweets was higher among men with the highest intake of the Western pattern.

\section{Dietary patterns and COPD}

The prudent pattern was inversely associated with the risk of newly diagnosed COPD after adjustment for age and total energy intake (table 2). This association remained statistically significant after adjustment for smoking (smoking, pack-years, pack-years ${ }^{2}$ ), and further adjustment for seven potential 
Table 1 Age standardised baseline characteristics by quintiles of 1986 pattern score

\begin{tabular}{|c|c|c|c|c|c|c|}
\hline & \multicolumn{3}{|c|}{ Quintiles for the prudent pattern } & \multicolumn{3}{|c|}{ Quintiles for the Western pattern } \\
\hline & $\begin{array}{l}\text { Quintile 1: } \\
\text { Small intake of } \\
\text { prudent diet }\end{array}$ & $\begin{array}{l}\text { Quintile3: } \\
\text { Medium intake of } \\
\text { prudent diet }\end{array}$ & $\begin{array}{l}\text { Quintile 5: } \\
\text { High intake of } \\
\text { prudent diet }\end{array}$ & $\begin{array}{l}\text { Quintile 1: } \\
\text { Small intake of } \\
\text { Western diet }\end{array}$ & $\begin{array}{l}\text { Quintile 3: } \\
\text { Medium intake of } \\
\text { Western diet }\end{array}$ & $\begin{array}{l}\text { Quintile 5: } \\
\text { High intake of } \\
\text { Western diet }\end{array}$ \\
\hline Current smokers (\%) & 16 & 7 & 5 & 5 & 8 & 14 \\
\hline Smoking (pack-years) & 15.8 & 11.4 & 9.2 & 9.6 & 11.6 & 15.1 \\
\hline White race/ethnicity (\%) & 90 & 91 & 91 & 88 & 91 & 93 \\
\hline No physician visits (\%) & 29 & 23 & 19 & 18 & 23 & 28 \\
\hline \multicolumn{7}{|l|}{ US region (\%) } \\
\hline East South Central & 5 & 4 & 4 & 3 & 4 & 6 \\
\hline Mountain & 7 & 8 & 8 & 6 & 8 & 8 \\
\hline Others regions & 88 & 88 & 89 & 91 & 87 & 86 \\
\hline Body mass index $\left(\mathrm{kg} / \mathrm{m}^{2}\right)$ & 25.6 & 25.5 & 25.2 & 25.0 & 25.5 & 25.9 \\
\hline Physical activity (METs/week) & 22 & 25 & 32 & 29 & 26 & 23 \\
\hline Multivitamin use (\%) & 19 & 20 & 21 & 21 & 20 & 18 \\
\hline Total energy (kcal) & 1622 & 1954 & 2432 & 1467 & 1899 & 2710 \\
\hline \multicolumn{7}{|l|}{ Food and nutrient consumption } \\
\hline Total vegetables (servings/day) & 1.4 & 2.6 & 5.2 & 3.1 & 2.8 & 3.0 \\
\hline Whole grain products (servings/day) & 0.5 & 1.0 & 1.9 & 1.0 & 1.1 & 1.2 \\
\hline Fruits (servings/day) & 0.9 & 1.5 & 2.8 & 2.2 & 1.8 & 1.7 \\
\hline Fish (servings/day) & 0.2 & 0.4 & 0.6 & 0.5 & 0.4 & 0.3 \\
\hline Desserts and sweets (servings/day) & 1.0 & 1.1 & 1.0 & 0.4 & 1.0 & 1.8 \\
\hline Cured meats (servings/day) & 0.4 & 0.4 & 0.3 & 0.1 & 0.3 & 0.7 \\
\hline Red meats (servings/day) & 0.6 & 0.6 & 0.6 & 0.2 & 0.6 & 1.1 \\
\hline Saturated fat (g) & 28.0 & 24.6 & 20.3 & 19.9 & 25.0 & 27.6 \\
\hline Monounsaturated fat $(\mathrm{g})$ & 30.0 & 27.5 & 23.7 & 22.9 & 27.7 & 30.2 \\
\hline Polyunsaturated fat (g) & 12.9 & 13.4 & 13.2 & 12.8 & 13.2 & 13.6 \\
\hline Trans fat (g) & 3.4 & 2.9 & 2.2 & 2.0 & 2.9 & 3.4 \\
\hline Total carbohydrates $(\mathrm{g})$ & 215 & 235 & 257 & 255 & 233 & 221 \\
\hline Total proteins (g) & 84.6 & 92.9 & 99.5 & 96.6 & 91.8 & 90.0 \\
\hline
\end{tabular}

confounders (race/ethnicity, physician visits, US region, BMI, physical activity, multivitamin use and energy intake) gave a similar result (table 2). Further adjustment for job title also led to a similar result: RR for highest vs lowest quintile 0.48 (95\% CI 0.24 to 0.94$), p$ for trend $=0.02$. Further adjustment for cardiovascular disease led to a borderline significant negative association: RR for highest vs lowest quintile 0.56 (95\% CI 0.28 to 1.13 ), $\mathrm{p}$ for trend $=0.06$.

By contrast, the Western pattern was positively and significantly associated with the risk of newly diagnosed COPD after taking age and total energy intake into account. Further adjustment for smoking and seven potential confounders continued to show a strong positive association. Further adjustment for job title also led to a similar result: RR for highest vs lowest quintile 4.61 (95\% CI 1.97 to 10.81 ), p for trend $<0.001$. Further adjustment for cardiovascular disease also led to similar results: RR for highest vs lowest quintile 3.72 (95\% CI 1.59 to 8.71 ), p for trend $<0.001$.

When the population was restricted to men without cancer or cardiovascular disease at baseline $(n=35286)$, similar associations were found: for the prudent pattern the RR for highest vs lowest quintile was 0.48 (95\% CI 0.23 to 1.01$)$, p for trend $=0.04$. By contrast, for the Western pattern the RR for highest vs lowest quintile was 3.46 (95\% CI 1.38 to 8.67$)$, p for trend $<0.001$.

\section{Dietary patterns and asthma}

Although the primary outcome of this study was newly diagnosed COPD, because of the potential overlap between the diagnoses of COPD and asthma, it was interesting to assess

Table 2 Association between quintiles of cumulative average patterns and newly diagnosed COPD

\begin{tabular}{|c|c|c|c|c|c|c|}
\hline & \multicolumn{5}{|c|}{ Quintile of intake } & \multirow[b]{2}{*}{$p$ for trend } \\
\hline & $\begin{array}{l}\text { Quintile 1: } \\
\text { Small intake }\end{array}$ & Quintile 2 & $\begin{array}{l}\text { Quintile 3: } \\
\text { Medium intake }\end{array}$ & Quintile 4 & $\begin{array}{l}\text { Quintile 5: } \\
\text { High intake }\end{array}$ & \\
\hline \multicolumn{7}{|l|}{ Prudent pattern } \\
\hline No of cases & 32 & 28 & 18 & 17 & 16 & \\
\hline Person-years & 50003 & 50105 & 49669 & 48830 & 48227 & \\
\hline $\operatorname{RR}(95 \% \mathrm{Cl})$ : adjustment $1^{*}$ & 1.00 & $0.60(0.36$ to 1.02$)$ & $0.40(0.22$ to 0.70$)$ & $0.30(0.17$ to 0.55$)$ & $0.20(0.11$ to 0.39$)$ & $<0.001$ \\
\hline $\mathrm{RR}(95 \% \mathrm{Cl})$ : adjustment $2 \dagger$ & 1.00 & $0.82(0.48$ to 1.39$)$ & $0.65(0.36$ to 1.15$)$ & 0.59 (0.32 to 1.09 ) & $0.47(0.24$ to 0.92$)$ & 0.02 \\
\hline RR (95\% Cl): adjustment $3 \ddagger$ & 1.00 & $0.83(0.49$ to 1.42$)$ & $0.64(0.36$ to 1.15$)$ & $0.60(0.32$ to 1.11$)$ & $0.50(0.25$ to 0.98$)$ & 0.02 \\
\hline \multicolumn{7}{|l|}{ Western pattern } \\
\hline No of cases & 12 & 9 & 16 & 29 & 45 & \\
\hline Person-years & 48958 & 49353 & 49663 & 49592 & 49268 & \\
\hline RR $(95 \% \mathrm{Cl})$ : adjustment 1* & 1.00 & $1.29(0.56$ to 2.96$)$ & $1.62(0.70$ to 3.78$)$ & 3.94 (1.76 to 8.79 ) & $10.49(4.62$ to 23.84$)$ & $<0.001$ \\
\hline $\mathrm{RR}(95 \% \mathrm{Cl})$ : adjustment $2 \dagger$ & 1.00 & 1.12 (0.49 to 2.58$)$ & $1.23(0.52$ to 2.86$)$ & 2.47 (1.11 to 5.52$)$ & $5.07(2.21$ to 11.66$)$ & $<0.001$ \\
\hline RR $(95 \% \mathrm{Cl})$ : adjustment $3 \ddagger$ & 1.00 & $1.09(0.48$ to 2.50$)$ & $1.15(0.49$ to 2.69$)$ & 2.30 (1.02 to 5.18$)$ & 4.56 (1.95 to 10.69$)$ & $<0.001$ \\
\hline
\end{tabular}

*Multivariate RRs adjusted for age and energy intake.

†Multivariate RRs adjusted for age, energy intake, smoking status, pack-years and pack-years ${ }^{2}$.

$\ddagger$ Multivariate RRs adjusted for age, energy intake, smoking status, pack-years, pack-years ${ }^{2}$, race/ethnicity, physician visits, US region, body mass index, physical activity and multivitamin use. 
Table 3 Association between quintiles of cumulative average patterns and adult-onset asthma

\begin{tabular}{|c|c|c|c|c|c|c|}
\hline & \multicolumn{5}{|c|}{ Quintile of intake } & \multirow[b]{2}{*}{$p$ for trend } \\
\hline & $\begin{array}{l}\text { Quintile 1: } \\
\text { Small intake }\end{array}$ & Quintile 2 & $\begin{array}{l}\text { Quintile 3: } \\
\text { Medium intake }\end{array}$ & Quintile 4 & $\begin{array}{l}\text { Quintile 5: } \\
\text { High intake }\end{array}$ & \\
\hline \multicolumn{7}{|l|}{ Prudent pattern } \\
\hline No of cases & 44 & 45 & 44 & 43 & 36 & \\
\hline Person-years & 49895 & 50003 & 49606 & 48745 & 48126 & \\
\hline RR $(95 \% \mathrm{Cl})$ : adjustment $7^{*}$ & 1.00 & 1.37 (0.88 to 2.12$)$ & $1.25(0.79$ to 1.96$)$ & $1.12(0.70$ to 1.79$)$ & 1.06 (0.64 to 1.73 ) & 0.80 \\
\hline RR $(95 \% \mathrm{Cl})$ : adjustment $2 \dagger$ & 1.00 & $1.29(0.83$ to 2.01$)$ & $1.14(0.72$ to 1.79$)$ & $1.00(0.62$ to 1.61$)$ & 0.93 (0.56 to 1.54$)$ & 0.42 \\
\hline RR $(95 \% \mathrm{CI})$ : adjustment $3 \ddagger$ & 1.00 & $1.29(0.83$ to 2.00$)$ & $1.13(0.72$ to 1.79$)$ & $0.99(0.61$ to 1.59$)$ & $0.91(0.55$ to 1.51$)$ & 0.37 \\
\hline \multicolumn{7}{|l|}{ Western pattern } \\
\hline No of cases & 30 & 42 & 46 & 50 & 44 & \\
\hline Person-years & 48864 & 49358 & 49639 & 49480 & 49034 & \\
\hline RR $(95 \% \mathrm{Cl})$ : adjustment $1^{*}$ & 1.00 & 1.07 (0.67 to 1.72 ) & 1.44 (0.90 to 2.28$)$ & 1.11 (0.67 to 1.85$)$ & $1.24(0.71$ to 2.14$)$ & 0.49 \\
\hline RR $(95 \% \mathrm{Cl})$ : adjustment $2 \dagger$ & 1.00 & 1.07 (0.67 to 1.72 ) & $1.45(0.91$ to 2.31$)$ & $1.13(0.68$ to 1.89$)$ & $1.29(0.74$ to 2.25$)$ & 0.40 \\
\hline RR $(95 \% \mathrm{Cl})$ : adjustment $3 \ddagger$ & 1.00 & $1.06(0.66$ to 1.71$)$ & $1.45(0.91$ to 2.31$)$ & 1.12 (0.67 to 1.88$)$ & $1.28(0.72$ to 2.25$)$ & 0.43 \\
\hline
\end{tabular}

*Multivariate RRs adjusted for age and energy intake.

†Multivariate RRs adjusted for age, energy intake, smoking status, pack-years and pack-years ${ }^{2}$.

$\ddagger$ Multivariate RRs adjusted for age, energy intake, smoking status, pack-years, pack-years ${ }^{2}$, race/ethnicity, physician visits, US region, body mass index, physical activity and multivitamin use.

the relation between dietary patterns and incident asthma in this cohort of men (table 3). In contrast to the risk of newly diagnosed COPD, no association was found between the prudent and Western patterns and the risk of adult-onset asthma.

\section{DISCUSSION}

In this large prospective cohort of US men, two distinct dietary patterns were identified using principal component analysis: the prudent pattern (loaded by a high consumption of fruits, vegetables, fish and whole grains) and the Western pattern (loaded by a high intake of refined grains, cured and red meats, desserts and sweets and French fries). During 12 years of follow-up, the risk of newly diagnosed COPD decreased as the prudent pattern score increased, whereas the risk of newly diagnosed COPD increased as the Western pattern score increased.

Studies on the association of individual foods and nutrients and COPD have suggested a beneficial effect of antioxidantsparticularly vitamin $\mathrm{C}$ and, to a lesser extent, vitamin $\mathrm{E}-\mathrm{on}$ COPD or $\mathrm{FEV}_{1}$ level. $^{5}$ However, there is no clear association between one particular food and COPD. Data from the $\beta$ Carotene and Retinol Efficacy Trial (CARET) conducted in the US which included 18341 heavy smokers and asbestos workers also indicated that vitamin A supplementation had no effect on the rate of decline of lung function in smokers and former smokers. ${ }^{22}$ Data from the $\alpha$-tocopherol and $\beta$-carotene Cancer Prevention Study (ATBC Study) conducted in Finland on 29133 men aged 50-69 years who were heavy smokers showed no reduction in COPD symptoms in those receiving $\beta$-carotene or $\alpha$-tocopherol supplements. ${ }^{23}$ Preliminary results from the Feasibility of Retinoids in the Treatment of Emphysema (FORTE) study, a multicentre clinical trial conducted in the US which included about 150 patients with emphysema, showed no change in respiratory symptoms, lung function testing, and CT scan lung density after supplementation with retinoic acid..$^{24}$ Although the effect of any individual nutrient in reducing the risk of COPD may be too small to detect, as suggested by these negative results, when several nutrients are consumed together, the cumulative effect may be sufficient for detection. Indeed, considering diet by an overall approach rather than by specific foods or nutrients may suggest a more comprehensive approach to disease prevention.

In this context, dietary patterns provide an overview of diet and are a good way to assess the relation between diet and newly diagnosed COPD. Dietary patterns have been investigated in relation to several diseases such as cardiovascular diseases, ${ }^{19}$ breast cancer $^{16}$ or diabetes, ${ }^{17}$ but few studies have examined the relationship between dietary patterns and respiratory diseases. Butler et al identified two patterns in 52325 adult Chinese Singaporean men and women aged 4574 years: one "vegetable, fruit, soy" pattern and one "meat-dim sum" pattern, corresponding to a high intake of chicken, pork, fish, rice and noodle dishes, and preserved foods. ${ }^{18}$ The "meatdim sum" pattern was associated with an increased risk of incident cough with phlegm. The second study was performed by our group in the Nurses' Health Study (unpublished data). Briefly, we identified two dietary patterns among 71 871 women aged 30-55 years in 1976: a prudent pattern highly loaded by intake of fruits, vegetables, fish and whole grain products, and a Western pattern highly loaded by intake of refined grains, processed and red meats, desserts and French fries. We found that the prudent pattern was associated with a decreased risk of newly diagnosed COPD between 1984 and 2000 and, by contrast, that the Western pattern was associated with an increased risk of newly diagnosed COPD.

Although the diet and lifestyle of Chinese Singaporeans are different from those in the US population, these findings are consistent with those from the female nurses and from the current study of male health professionals. All three studies suggest a deleterious effect of a diet rich in meat, starchy foods and high-fat dairy products on COPD. The Western diet is highly loaded by processed meats, one of the most important compounds of which is nitrite. Nitrites generate reactive nitrogen species which provoke nitrosative stress; this may contribute to the progressive deterioration in pulmonary function. ${ }^{25}$ The Western diet also was loaded by a high intake of foods with a high glycaemic index (refined grains, desserts, sweets). It has been suggested that hyperglycaemia is related to impaired lung function, ${ }^{26}$ which remains the main measurement for diagnosis of COPD. ${ }^{27}$ Furthermore, both hyperglycaemia and COPD are positively related to inflammation, ${ }^{28}{ }^{29}$ even if the causal association between COPD and systemic inflammation remains unclear. ${ }^{30}$ As several foods from the Western diet (such as cured meat and refined grains) might be related to COPD, the Western pattern offers a good way of summarising the possible effects of these diverse but highly correlated foods.

The finding that the prudent pattern (loaded by fruits and vegetables) is associated with a decreased risk of newly diagnosed COPD is consistent with previous epidemiological 
literature suggesting a beneficial effect of antioxidantsparticularly vitamin $\mathrm{C}$ and, to a lesser extent, vitamin $\mathrm{E}-\mathrm{on}$ COPD or $\mathrm{FEV}_{1}$ level. ${ }^{5}$ Butler et al ${ }^{18}$ also reported a weak association between their fruits-vegetables-soy pattern and cough with phlegm which disappeared after adjustment for non-starch polysaccharide. Non-starch polysaccharide is a major component of dietary fibre and of some non-citrus fruits. In our study, whole grain products are included in the prudent pattern. Although the consumption of fibre and whole grain has not been studied to any extent in relation to COPD, Butler et al reported in this population of Singaporean Chinese that a diet high in fibre may reduce the incidence of cough with phlegm. ${ }^{31}$ In a cross-sectional study, Tabak et al ${ }^{32}$ reported a positive association between whole grain consumption and the prevalence of COPD in 13651 men from the MORGEN study. The prudent pattern also was loaded by a high intake of fish, one of the main sources of omega-3 polyunsaturated fatty acids, but the results are still inconsistent across studies ${ }^{5}$ and the only published prospective study observed no relation between intake of omega-3 and the incidence of chronic nonspecific lung disease. ${ }^{9}$

Principal component analysis to derive dietary patterns involves several arbitrary decisions on the selection of included variables, the construction of the food groups, the number of retained factors, the method of rotation and the labels of the factors. ${ }^{33}$ In this cohort of men, multiple sensitivity analyses were performed to assess the reproducibility and the robustness of these dietary patterns. ${ }^{17}$ Similar patterns were identified after using the maximum likelihood method instead of the principal component method to extract initial factors, after using an oblique rotation instead of an orthogonal one, after retaining three patterns instead of two, and even after deriving dietary patterns based on the 131 individual food items rather than from the predefined food groups. ${ }^{17}$

In addition to these statistical considerations, our study has other potential limitations. First, we acknowledge that the association between dietary patterns and newly diagnosed COPD may be due in part to a residual confounding by cigarette smoking. To minimise this possibility, multivariate models were adjusted with multiple measures of tobacco exposure (smoking habits, pack-years and (pack-years) ${ }^{2}$ ), but residual confounding by smoking remains a possibility. Furthermore, we were not able to adjust for environmental tobacco smoke, which remains an important risk factor for COPD. ${ }^{34}$ However, analyses were adjusted for environmental tobacco smoke in the Nurses' Health Study and it did not change the result (unpublished data). Second, newly diagnosed COPD was defined by a selfreported physician diagnosis of COPD and no lung function results were available. However, the questionnaire-based definition of newly diagnosed COPD was validated in a subset of a similar population of female health professionals. ${ }^{21}$ The low rate of COPD in this population is probably due to the low smoking rates among health professionals. The main source of misclassification was a misdiagnosis with asthma, but our findings for asthma diagnosis were null. While we acknowledge the potential for some misclassifications, these data allowed us to investigate the relationship between dietary patterns and COPD in a very large population, with repeated measurements of both diet and COPD. Finally, due to the relatively small number of cases $(n=111)$, it was not possible to perform stratified analyses according to smoking status or BMI. BMI is considered as a marker of low-grade systemic inflammation, and we would have liked to examine possible effect modification by this factor. Celli et al have recently suggested that BMI is an important factor in the severity of COPD, ${ }^{35}$ and in the Nurses' Health Study we reported a significant interaction between BMI and the Western pattern. The association between the Western pattern and the risk of newly diagnosed COPD was stronger in lean women (BMI $\leqslant 20 \mathrm{~kg} / \mathrm{m}^{2}$ ) than in others, but the mechanism for the observed interaction requires further study.

In summary, we report the first study on dietary patterns in relation to the risk of newly diagnosed COPD in men. We identified two major dietary patterns - the prudent and the Western patterns-and found that both were associated with a risk of newly diagnosed COPD. The prudent pattern was negatively associated with the risk of newly diagnosed COPD while the Western pattern was positively associated with the risk of newly diagnosed COPD. Temporal changes in dietary patterns may contribute to ongoing increases in COPD.

\section{ACKNOWLEDGEMENTS}

The authors thank Rong Chen for her help with the dataset.

\section{Authors' affiliations \\ Raphaëlle Varraso, Frank B Hu, Walter Willett, Department of Nutrition, Harvard School of Public Health, Boston, Massachusetts, USA \\ Teresa T Fung, Department of Nutrition, Simmons College, Boston, \\ Massachusetts, USA \\ Carlos A Camargo, Department of Emergency Medicine, Massachusetts General Hospital, Harvard Medical School, Boston, Massachusetts, USA}

Supported by research grant CA55075 and HL60712 from the National Institutes of Health (Bethesda, MD, USA). RV was supported by grants from the Société de Pneumologie de Langue Française (Paris, France) and the Société Française de Nutrition (Paris, France).

Competing interests: RV, TTF, FBH, WW: None declared. CAC has received financial support from a variety of groups for participation in conferences, consulting and medical research. During 2002-2006, industry sponsors with an interest in COPD were Altana, Astra Zeneca, Aventis Pasteur, Aventis, Boehringer Ingelheim, Dey, GSK, Janssen, Med Immune, Merck, Novartis, Pfizer, Respironics and Schering-Plough. CAC did not receive any financial support from the food and beverage industries.

\section{REFERENCES}

1 Pauwels RA, Buist AS, Calverley PM, et al. Global strategy for the diagnosis, management, and prevention of chronic obstructive pulmonary disease. NHLBI/ WHO Global Initiative for Chronic Obstructive Lung Disease (GOLD) Workshop summary. Am J Respir Crit Care Med 2001;163:1256-76.

2 Murray CJ, Lopez AD. Alternative projections of mortality and disability by cause 1990-2020: Global Burden of Disease Study. Lancet 1997;349:1498-504.

3 Peto R, Lopez AD, Boreham J, et al. Mortality from tobacco in developed countries: indirect estimation from national vital statistics. Lancet 1992:339: 1268-78

4 Devereux G. ABC of chronic obstructive pulmonary disease. Definition, epidemiology, and risk factors. BMJ 2006;332:1142-4

5 Romieu I. Nutrition and lung health. Int J Tuberc Lung Dis 2005;9:362-74

6 Kelly Y, Sacker A, Marmot M. Nutrition and respiratory health in adults: findings from the health survey for Scotland. Eur Respir J 2003;21:664-71.

7 Britton JR, Pavord ID, Ricahrds A, et al. Dietary antioxidant vitamin intake and lung function in the general population. Am J Respir Crit Care Med 1995; 151:1138-87

8 Schunemann HJ, McCann S, Grant BJ, et al. Lung function in relation to intake of carotenoids and other antioxidant vitamins in a population-based study. Am J Epidemiol 2002;155:463-71.

9 Miedema I, Feskens EJ, Heederik D, et al. Dietary determinants of long-term incidence of chronic nonspecific lung diseases. The Zutphen Study. Am J Epidemiol 1993; 138:37-45.

10 Carey IM, Strachan DP, Cook DG. Effects of changes in fresh fruit consumption on ventilatory function in healthy British adults. Am J Respir Crit Care Med 1998;158:728-33.

11 Butland BK, Fehily AM, Elwood PC. Diet, lung function, and lung function decline in a cohort of 2512 middle aged men. Thorax 2000;55:102-8.

12 McKeever TM, Scrivener S, Broadfield E, et al. Prospective study of diet and decline in lung function in a general population. Am J Respir Crit Care Med 2002;165:1299-303.

13 Tabak C, Feskens EJ, Heederik D, et al. Fruit and fish consumption: a possible explanation for population differences in COPD mortality (The Seven Countries Study). Eur J Clin Nutr 1998;52:819-25.

14 Shahar E, Folsom AR, Melnick SL, et al. Dietary n-3 polyunsaturated fatty acids and smoking-related chronic obstructive pulmonary disease. N Engl J Med 1994;331:228-33. 
15 Slattery ML, Boucher KM, Caan BJ, et al. Eating patterns and risk of colon cancer. Am J Epidemiol 1998;148:4-16.

16 Fung $\Pi$, Hu FB, Holmes MD, et al. Dietary patterns and the risk of postmenopausal breast cancer. Int J Cancer 2005;116:116-21.

17 van Dam RM, Rimm EB, Willett WC, et al. Dietary patterns and risk for type 2 diabetes mellitus in U.S. men. Ann Intern Med 2002;136:201-9.

18 Butler LM, Koh WP, Lee HP, et al. Prospective study of dietary patterns and persistent cough with phlegm among Chinese Singaporeans. Am J Respir Crit Care Med 2006; 173:264-70.

19 Hu FB, Rimm EB, Stampfer MJ, et al. Prospective study of major dietary patterns and risk of coronary heart disease in men. Am J Clin Nutr 2000;72:912-21.

20 Joliffe IT, Morgan BJ. Principal component analysis and exploratory factor analysis. Stat Methods Med Res 1992;1:69-95.

21 Barr RG, Herbstman J, Speizer FE, et al. Validation of self-reported chronic obstructive pulmonary disease in a cohort study of nurses. Am J Epidemiol 2002; 155:965-71.

22 Balmes J, Ngo L, Keogh J, et al. Effect of supplemental B-carotene and retinol rate of decline in lung function. Am J Respir Crit Care Med 1998;157:A46.

23 Rautalahti M, Virtamo J, Haukka J, et al. The effect of alpha-tocopherol and beta-carotene supplementation on COPD symptoms. Am J Respir Crit Care Med 1997; 156: 1447-52.

24 Roth MD, Connett JE, D'Armiento J, et al. Feasibility of retinoids for the treatment of emphysema study. Chest, 2006, in press.

25 Ricciardolo FL, Di Stefano A, Sabatini F, et al. Reactive nitrogen species in the respiratory tract. Eur J Pharmacol 2006;533:240-52.

26 Walter RE, Beiser A, Givelber RJ, et al. Association between glycemic state and lung function: the Framingham Heart Study. Am J Respir Crit Care Med 2003; 167:911-6.

27 Celli BR, MacNee W. Standards for the diagnosis and treatment of patients with COPD: a summary of the ATS/ERS position paper. Eur Respir J 2004;23:932-46.

28 Donaldson GC, Seemungal TA, Patel IS, et al. Airway and systemic inflammation and decline in lung function in patients with COPD. Chest 2005; 128:1995-2004.

29 Esposito K, Nappo F, Marfella R, et al. Inflammatory cytokine concentrations are acutely increased by hyperglycemia in humans: role of oxidative stress. Circulation 2002; 106:2067-72.

30 Gan WQ, Man SF, Senthilselvan A, et al. Association between chronic obstructive pulmonary disease and systemic inflammation: a systematic review and a meta-analysis. Thorax 2004;59:574-80.

31 Butler LM, Koh WP, Lee HP, et al. Dietary fiber and reduced cough with phlegm: a cohort study in Singapore. Am J Respir Crit Care Med 2004;170:279-87.

32 Tabak C, Smit HA, Heederik D, et al. Diet and chronic obstructive pulmonary disease: independent beneficial effects of fruits, whole grains, and alcohol the MORGEN study). Clin Exp Allergy $2001 ; 31: 747-55$.

33 Hu FB. Dietary pattern analysis: a new direction in nutritional epidemiology. Curr Opin Lipidol 2002;13:3-9.

34 Eisner MD, Balmes J, Katz PP, et al. Lifetime environmental tobacco smoke exposure and the risk of chronic obstructive pulmonary disease. Environ Health 2005;4:7.

35 Celli BR, Cote CG, Marin JM, et al. The body-mass index, airflow obstruction, dyspnea, and exercise capacity index in chronic obstructive pulmonary disease. N Engl J Med 2004;350:1005-12.

\section{APPENDIX A}

Food groupings for factor analysis

\begin{tabular}{|c|c|}
\hline Foods or food groups & Food items \\
\hline $\begin{array}{l}\text { Processed meats } \\
\text { Red meats }\end{array}$ & $\begin{array}{l}\text { Hot dogs, processed meats, bacon } \\
\text { Hamburger, beef, pork, lamb }\end{array}$ \\
\hline Organ meats & Liver \\
\hline Fish & Canned tuna, dark meat fish, oily fish, shrimp \\
\hline Poultry & Chicken or turkey with or without skin \\
\hline Eggs & Eggs \\
\hline Butter & Butter \\
\hline Margarine & Margarine \\
\hline Low-fo & k, yogurt, sherbet, cottage cheese \\
\hline High-fat dairy & $\begin{array}{l}\text { Whole milk, cream, sour cream, cream cheese, } \\
\text { ice cream, other cheese }\end{array}$ \\
\hline Liquor & Liquor \\
\hline & White wine, red wine \\
\hline Bee & Beer \\
\hline Tea & $\mathrm{Te}$ \\
\hline Coffee & Regular coffee, decaffeinated coffee \\
\hline Fruit & $\begin{array}{l}\text { Raisins, avocado, orange, grapefruit, banana, } \\
\text { cantaloupe, water melon, apple, strawberry, } \\
\text { blueberry, peach, apricots, plums }\end{array}$ \\
\hline Fruit juice & $\begin{array}{l}\text { Orange juice, apple juice, grapefruit juice, other } \\
\text { juice }\end{array}$ \\
\hline Cruciferous vegetables & $\begin{array}{l}\text { Broccoli, cabbage, kale, cauliflower, Brussels } \\
\text { sprouts }\end{array}$ \\
\hline Yellow vegetables & Carrots, yellow squash, yam \\
\hline Tomatoes & Tomatoes, tomato juice, tomato sauce \\
\hline Leafy & $\begin{array}{l}\text { Raw spinach, cooked spinach, iceberg lettuce, } \\
\text { romaine or leaf lettuce }\end{array}$ \\
\hline Legu & Tofu, string bean, peas, beans or lentils \\
\hline Othe & $\begin{array}{l}\text { Corn, mixed vegetables, eggplant, celery, } \\
\text { mushroom, beets, alfalfa sprouts }\end{array}$ \\
\hline Potatoes & Potatoes \\
\hline & nch fries \\
\hline Wh & $\begin{array}{l}\text { Dark breads, oat bran, brown rice, wheat germ, } \\
\text { oats, cooked cereal, whole grain ready-to-eat } \\
\text { cereals, other grains }\end{array}$ \\
\hline Refined grains & $\begin{array}{l}\text { White bread, white rice, English muffins, pasta, } \\
\text { pancake, refined grain ready-to-eat cereals }\end{array}$ \\
\hline $\mathrm{Sn}$ & Potato chips, popcorn, crackers \\
\hline & Peanut butter, nuts \\
\hline Sugar beverages & $\begin{array}{l}\text { Cola, caffeine-free cola, fruit punch, other } \\
\text { carbonated beverages }\end{array}$ \\
\hline Low-calorie beverages & $\begin{array}{l}\text { Diet cola, diet caffeine-free cola, other diet } \\
\text { carbonated beverages }\end{array}$ \\
\hline Desserts/sweets & $\begin{array}{l}\text { Chocolate bars or pieces, candy bars, cookies, } \\
\text { brownies, doughnuts, cake, pie, sweet roll, coffee } \\
\text { cake, pastry }\end{array}$ \\
\hline Garli & Garlic \\
\hline Condin & $\begin{array}{l}\text { Jam, mustard, pepper, salt, chilli sauce, coffee, } \\
\text { whitener }\end{array}$ \\
\hline Salad & Oil and vinegar type dressings \\
\hline & \\
\hline Mayonnaise & Mayonnaise-type salad dressings \\
\hline Pizza & Pizza \\
\hline Olive oil* & Olive oil \\
\hline
\end{tabular}

*These items were available only on the 1990 and 1994 food frequency questionnaires. 